\title{
A Miniascape-Like Triple-Band Monopole Antenna for WBAN Applications
}

\author{
Chun-Ping Deng, Xiong-Ying Liu, Member, IEEE, Zhen-Kun Zhang, and Manos M. Tentzeris, Fellow, IEEE
}

\begin{abstract}
A miniascape-like triple-band monopole antenna designed for wireless body area network (WBAN) applications is presented in this letter. With a miniascape-like strip composed of an S-shaped strip, a U-shaped strip, and an I-shaped strip, three operating bands covering 3.1-3.3, 4.2-4.9 and 6-10.6 GHz for VSWR $\leqslant 2$ are obtained, respectively. A quarter-circle cutting from the ground enhances the impedance match in the higher frequency band. Compared to previous wireless body area network antennas, the proposed antenna achieves a compact size of $23.6 \times 35 \mathrm{~mm}^{2}$ with low profile (thickness of $0.05 \mathrm{~mm}$ ) and can conform to the human body. The experimental results for the VSWR characteristics and radiation patterns show good agreement with the simulated ones.
\end{abstract}

Index Terms-Coplanar waveguide (CPW), triple-band antenna, ultrawideband (UWB), wireless body area network (WBAN).

\section{INTRODUCTION}

W IRELESS body area network (WBAN) represents wireless communications on, near, and around the human body between several miniaturized body sensors and a single wearable center. It allows inexpensive and continuous health monitoring with real-time updates of medical records via the Internet. As there is rapid growth in wireless physiological sensors, WBAN is attracting more attention from the research community. Ultrawideband (UWB) technology is a good candidate for WBAN applications due to its low emission power and high data rates. Both lower band (3.1-4.9 GHz) and higher band $(6.0-10.6 \mathrm{GHz})$ in the UWB frequency range could be utilizable to WBAN applications [1].

The antenna plays a critical role in the wireless body area network system because it can influence the complexity of the receiver and transmitter design. Several studies provide some UWB antennas for WBAN applications [2]-[10]. In [2], a 3-D UWB directional antenna is investigated. However, the UWB directional antenna is so high that it will obstruct the human daily activities when applied to the human body. Therefore,

Manuscript received August 11, 2012; revised September 29, 2012; accepted October 23, 2012. Date of publication November 16, 2012; date of current version December 04, 2012. This work was supported in part by the National Natural Science Foundation of China under Grant 60802004 and the Guangdong Province Natural Science Foundation under Grant 9151064101000090.

C.-P. Deng, X.-Y. Liu, and Z.-K. Zhang are with the School of Electronic and Information Engineering, South China University of Technology, Guangzhou 510640, China (e-mail: liuxy@scut.edu.cn).

M. M. Tentzeris is with the Department of Electrical Engineering, Georgia Institute of Technology, Atlanta, GA 30332 USA.

Color versions of one or more of the figures in this letter are available online at http://ieeexplore.ieee.org.

Digital Object Identifier 10.1109/LAWP.2012.2227292

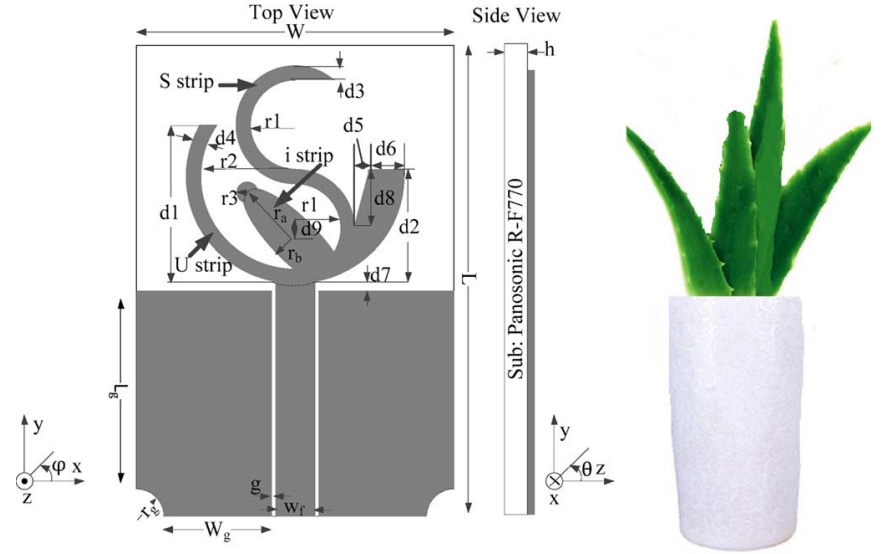

Fig. 1. Geometry of the proposed antenna.

planar antennas with low height are widely developed. In [3], a microstrip-fed tapered monopole antenna is studied. However, it only works at $2.7-7.9-\mathrm{GHz}$ band, which is not wide enough for the UWB system and cannot conform to the human body. Consequently, wearable and flexible antennas are introduced. In [4], a coplanar waveguide (CPW)-fed textile UWB antenna for the wireless body area network is presented, which operates in the entire UWB band. However, the textile material is not easy to implement its CPW feeding transmission line with $0.5 \mathrm{~mm}$ gap. In addition, the fully used UWB frequency range of 3.1-10.6 GHz will influence existing wireless communication systems, such as the wireless local area network (WLAN) operating in 5.15-5.825-GHz band, WiMAX system covering the 3.3-3.7-GHz band, and C-band (3.7-4.2 GHz) satellite communication system. The electromagnetic compatibility between the UWB system and other wireless communication systems ought to be considered.

In this letter, a compact CPW-fed triple-band monopole antenna with a miniascape-like strip is proposed. Due to the advantage of flexibility, small dimension, and light weight, it can be conformal to the human body and used in wearable devices for medical monitoring. By using an S-shaped strip, a U-shaped strip, and an I-shaped strip, 3.1-3.3-, 4.2-4.9-, and 6-10.6-GHz bands in UWB (3.1-10.6 GHz) are covered, which make it coexist with other wireless communication systems.

\section{ANTENNA DESIGN}

The proposed WBAN antenna as shown in Fig. 1 is printed on a flexible Panasonic R-F770 substrate with relative permittivity $\varepsilon_{\mathrm{r}}=3.2$, loss tangent $\tan \delta=0.002$, thickness $h=$ $0.05 \mathrm{~mm}$, and dimension of $23.6 \times 35 \mathrm{~mm}^{2}$. It is fed by a $50-\Omega$ 


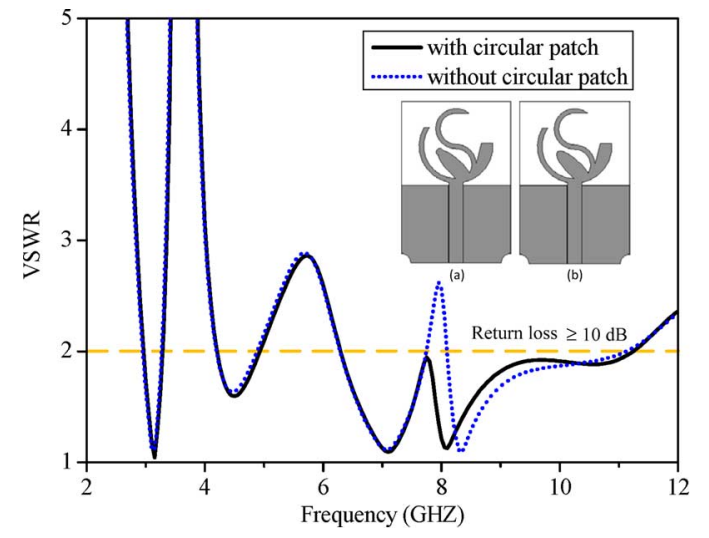

Fig. 2. Simulated VSWR of the proposed antenna (a) with circular patch and (b) without circular patch.

CPW line of width $3 \mathrm{~mm}$ and gap $0.1 \mathrm{~mm}$. Using a patch composed of an S-shaped strip, a U-shaped strip, and an I-shaped strip, the antenna looks like a miniascape. Good impedance matching for VSWR $\leqslant 2$ in 3.1-3.3, 4.2-4.9, and 6-10.6 GHz is achieved. To diminish the size of the antenna, the S-shaped strip is used to make the antenna resonate at $3.2 \mathrm{GHz}$ for the lower interested band. The total length of the S-shaped strip is about $17 \mathrm{~mm}$, which is approximately a quarter wavelength at $3.2 \mathrm{GHz}$. In addition, the left part of the U-shaped strip works at $4.5-\mathrm{GHz}$ band with a quarter wavelength at $4.5 \mathrm{GHz}$; a tapered structure is added to the right part of the U-shaped strip to achieve broadband. With the co-action between the higher mode of the S-shaped strip and the right part of the U-shaped strip, $6.35-7.8-\mathrm{GHz}$ band is covered. In order to broaden the bandwidth around the higher frequencies, we add an I-shaped strip to generate an additional resonance around $8.1 \mathrm{GHz}$. To make the best use of the available space, the I-shaped strip is extended to the region between the S-shaped strip and the left U-shaped strip. An elliptical patch is attached to the I-shaped strip to cover the band of 7.8-11 GHz. The frequency corresponding to the lower edge of the bandwidth is given as [11]

$$
f=\frac{c}{\lambda}=\frac{72}{l+r} \quad(\mathrm{GHz})
$$

where $l$ is the height of the planar elliptical monopole, and $r$ is the effective radius given by $2 \pi r l=\pi a b$ ( $a$ and $b$ are the major and minor axial length of ellipse, respectively). A circular patch is added to the top of the elliptical patch to lower the resonant frequency, as shown in Fig. 2. To ensure good impedance match in the higher frequency band, a quarter circle is cut from the ground. During the design process, geometrical dimensions are first studied in detail by simulation with the aid of the Ansoft HFSS electromagnetic software, and then the prototype is fabricated and measured for verification. Through adjusting the geometric parameters of the proposed antenna, we finally obtained the optimal dimensions of the antenna to be $W=23.6 \mathrm{~mm}$, $L=35 \mathrm{~mm}, W g=9.8 \mathrm{~mm}, L g=14.8 \mathrm{~mm}, r_{\mathrm{g}}=2 \mathrm{~mm}$, $w_{\mathrm{f}}=3 \mathrm{~mm}, g=0.1 \mathrm{~mm}, r 1=3.4 \mathrm{~mm}, r 2=7 \mathrm{~mm}$, $r 3=0.8 \mathrm{~mm}, r_{\mathrm{a}}=5.1 \mathrm{~mm}, r_{\mathrm{b}}=1.7 \mathrm{~mm}, d 1=11.9 \mathrm{~mm}$, $d 2=8.6 \mathrm{~mm}, d 3=1 \mathrm{~mm}, d 4=1 \mathrm{~mm}, d 5=1.1 \mathrm{~mm}$, $d 6=2.5 \mathrm{~mm}, d 7=0.6 \mathrm{~mm}, d 8=4.4 \mathrm{~mm}, d 9=0.7 \mathrm{~mm}$.

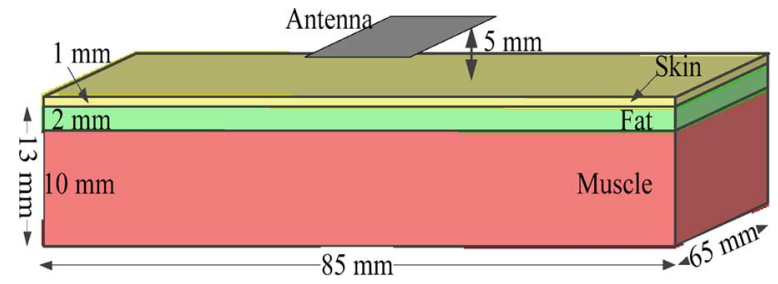

Fig. 3. Three-layer tissue model.

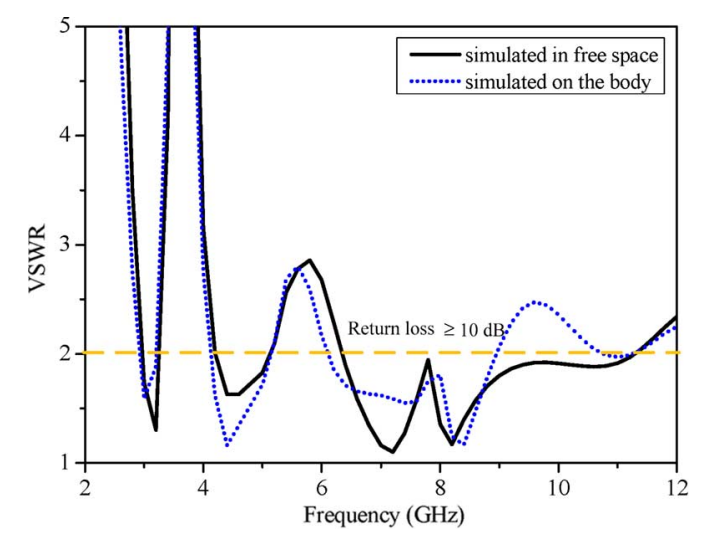

Fig. 4. Simulated VSWR of the proposed antenna in free space and on the human body.

TABLE I

HUMAN BODY CHARACTERISTICS AT $7 \mathrm{GHz}$

\begin{tabular}{lcc}
\hline \hline \multicolumn{1}{c}{ Layer } & $\begin{array}{c}\text { Relative dielectric } \\
\text { constant }\end{array}$ & Conductivity (S/m) \\
\hline Skin $(1 \mathrm{~mm})$ & 34 & 4.8 \\
Fat $(2 \mathrm{~mm})$ & 4.8 & 0.37 \\
Muscle $(10 \mathrm{~mm})$ & 47 & 6 \\
\hline \hline
\end{tabular}

\section{RESULTS AND DISCUSSIONS}

\section{A. Simulation Results and Discussion}

To study the effects of a human body on the antenna performance, we assume that the antenna is placed $5 \mathrm{~mm}$ away from a three-layer (skin, fat, and muscle) tissue model as shown in Fig. 3 with a total dimension of $85 \times 65 \times 13 \mathrm{~mm}^{2}$. The human body characteristics at $7 \mathrm{GHz}$ are shown in Table I [6]. Fig. 4 shows the simulated VSWRs of the proposed antenna in free space and on the human body. In free space, the frequency bands for VSWR $\leqslant 2$ are 3.1-3.3, 4.2-4.9, and 6-10.6 GHz. If the three-layer tissue model is introduced, the impedance matching will become worse due to the electrical property of a human body, but is still acceptable.

Stronger current distributions as shown in Fig. 5 happen at the center frequency of $3.2,4.5,7$, and $8.1 \mathrm{GHz}$, respectively.

\section{B. Measurement Results and Discussion}

Fig. 6 shows a photograph of the fabricated flexible antenna. A 50- $\Omega$ SMA connector is connected to the CPW for measurement. Fig. 7 shows the simulated and measured VSWR of the proposed antenna in free space using an Agilent N5230A vector network analyzer. To investigate the effect of the presence of the human body, the antenna is placed on the left arm. Fig. 8 


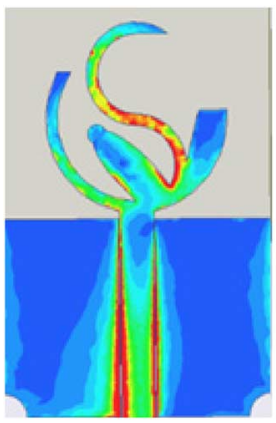

(a)

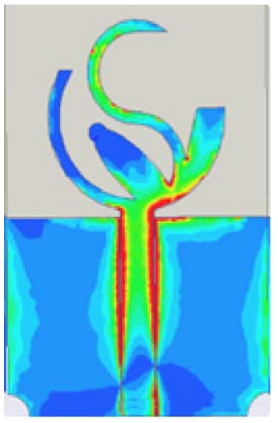

(c)

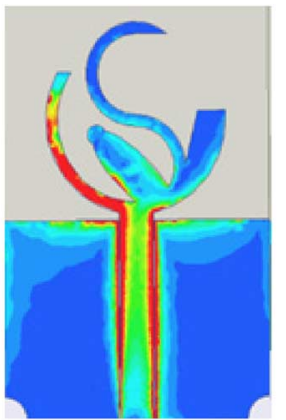

(b)

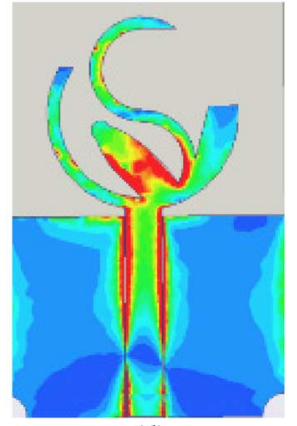

(d)
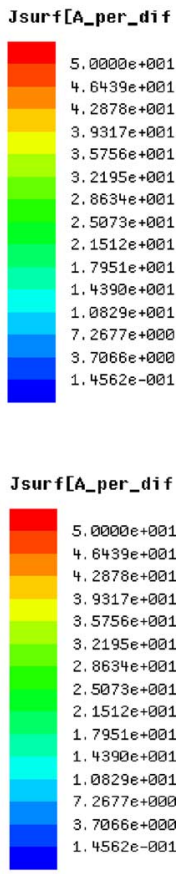

$4562 e-001$
Fig. 5. Current distributions of the proposed antenna at (a) 3.2, (b) 4.5, (c) 7 , and (d) $8.1 \mathrm{GHz}$.

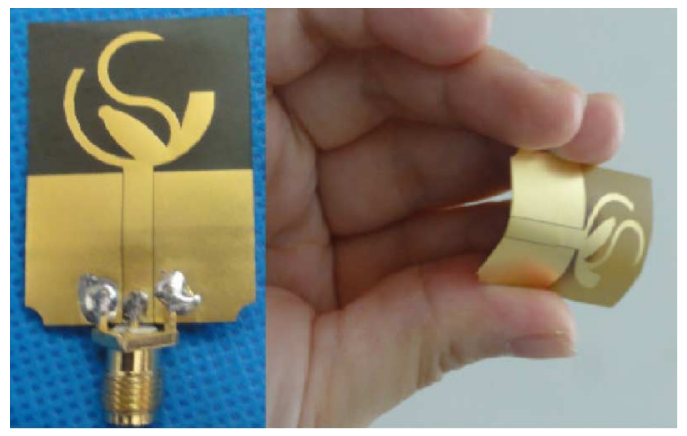

Fig. 6. Practical prototype of the fabricated flexible antenna.

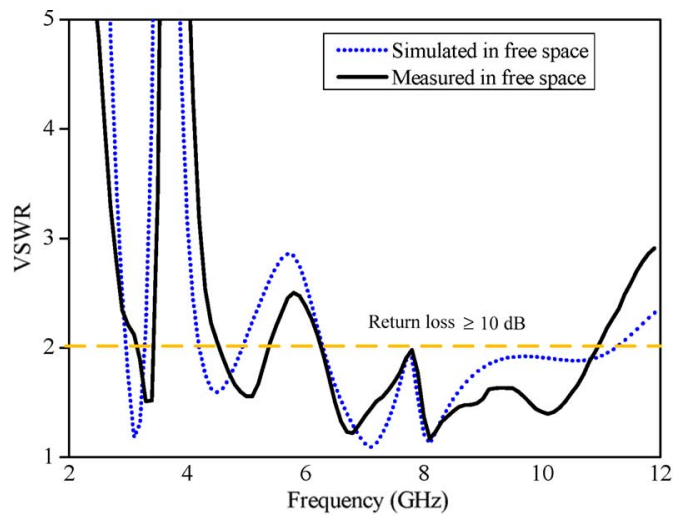

Fig. 7. Measured and simulated VSWR of the proposed antenna in free space.

shows the simulated and measured VSWR results. It can be observed that VSWR $\leqslant 2$ is satisfied in 2.9-3.3-, 4.5-5.2-, and 6.4-11.7-GHz bands on the human body. The VSWRs of the

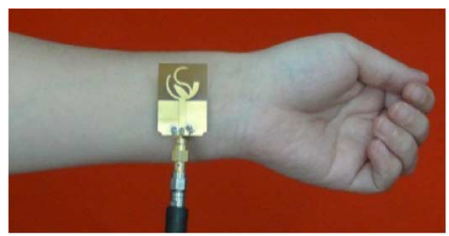

(a)

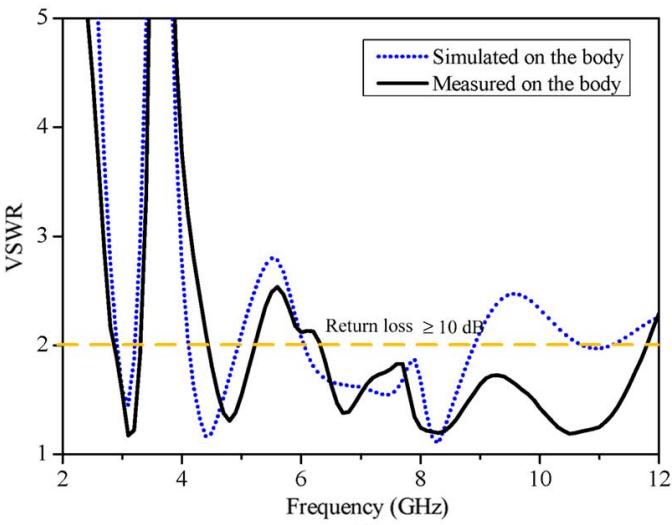

(b)

Fig. 8. Proposed antenna on the human body. (a) Antenna mounted on the arm (b) Measured and simulated VSWR.

designed antenna measured on the body are better than the simulated ones at higher frequency band due to the interference with the connector and lossy human body (with increased conductivity at high frequencies).

Fig. 9 shows the simulated and measured radiation patterns of the designed antenna in free space and on the human body at 3.2, 4.5 , and $7 \mathrm{GHz}$, respectively. The radiation patterns are measured in an anechoic chamber that is located at Samsung Guangzhou Mobile R\&D Center, Guangzhou, China, with an AirLink 3D software. The proposed UWB patch antenna has a dipole-shape radiation pattern in the $x o y$-plane (E-plane) and an omnidirectional radiation pattern in xoz-plane (H-plane). However, the designed antenna on body has directional radiation patterns due to the superposition of back radiation and radiation from the human body. The measured patterns agree well with the simulated ones, while some minor discrepancies can be attributed to the measurement environment and lossy human body between simulation and measurement. The gains and efficiencies of the antenna in free space and on the body are displayed in Table II, respectively. Although the performance is slightly higher than that of the UWB antenna mentioned in [7], the gains and the efficiencies on the body still deteriorate due to the mismatch and loss caused by human tissues.

\section{Bending the Antenna}

An antenna's performance under bending conditions needs to be considered for WBAN applications [12]. In order to evaluate the performance of the antenna when placed in an on-body environment, the antennas are tested under the condition of conforming to the human arm. Fig. 10 shows the measured VSWR for the conformal antenna. The proposed antenna exhibits a low susceptibility to impedance mismatch and resonant frequency shift due to bending effects. It clarifies that the proposed antenna is suitable in both flat and bending conditions. 

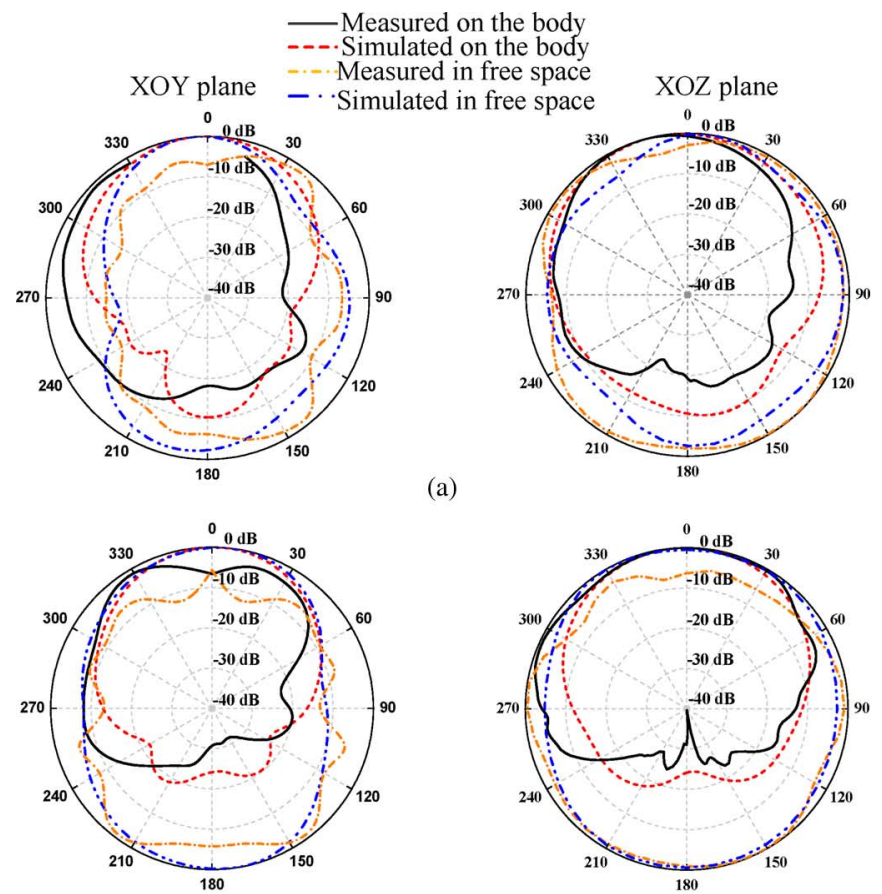

(b)
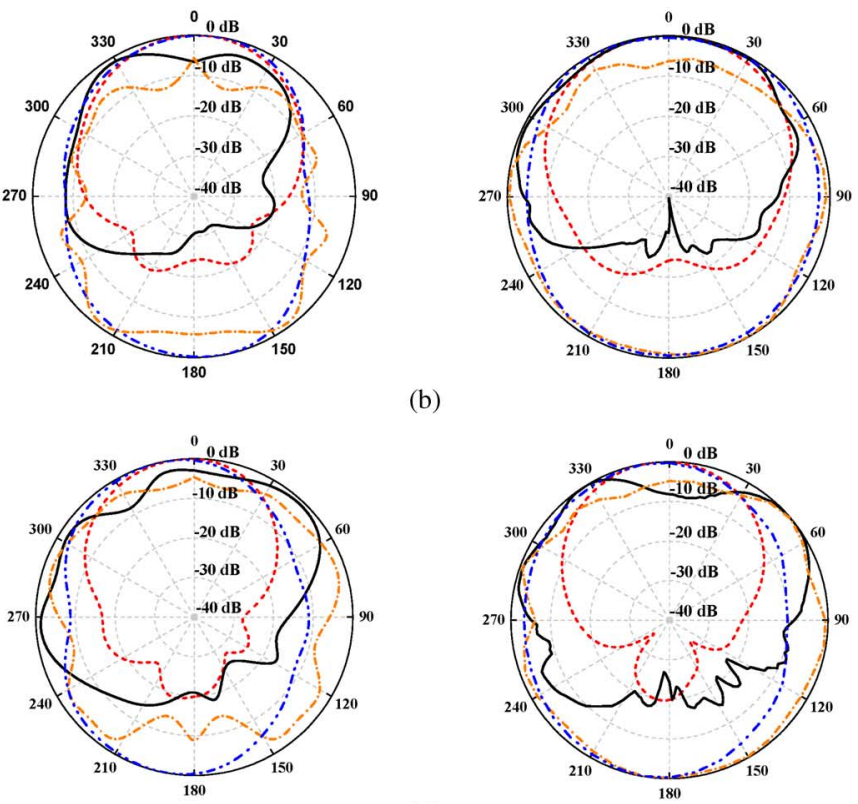

(c)

Fig. 9. Measured and simulated radiation patterns of the proposed antenna in free space and on the human body. (a) $3.2 \mathrm{GHz}$. (b) $4.5 \mathrm{GHz}$. (c) $7 \mathrm{GHz}$.

TABLE II

GAINS AND EFFICIENCIES OF THE ANTENNA IN DIFFERENT CONDITIONS

\begin{tabular}{|c|c|c|c|c|c|c|}
\hline \multirow[b]{2}{*}{$\begin{array}{c}\text { Freque } \\
\text { ncy } \\
(\mathrm{GHz})\end{array}$} & \multicolumn{3}{|c|}{ In free space } & \multicolumn{3}{|c|}{ On the body } \\
\hline & $\begin{array}{c}\text { Average } \\
\text { Gain } \\
(\mathrm{dBi})\end{array}$ & $\begin{array}{l}\text { Peak } \\
\text { Gain } \\
(\mathrm{dBi})\end{array}$ & $\begin{array}{c}\text { Efficie } \\
\text { ncy }\end{array}$ & $\begin{array}{l}\text { Average } \\
\text { Gain } \\
(\mathrm{dBi})\end{array}$ & $\begin{array}{l}\text { Peak } \\
\text { Gain } \\
(\mathrm{dBi})\end{array}$ & $\begin{array}{c}\text { Efficie } \\
\text { ncy }\end{array}$ \\
\hline 3.2 & -0.5 & 4.4 & $89.2 \%$ & -5.2 & 2.2 & $30.3 \%$ \\
\hline 4.5 & -0.6 & 5.3 & $87.4 \%$ & -3.5 & 3.7 & $45.0 \%$ \\
\hline 7 & -0.3 & 7.5 & $93.4 \%$ & -2 & 6.9 & $62.7 \%$ \\
\hline
\end{tabular}

\section{CONCLUSION}

This letter has demonstrated a miniascape-like triple-band monopole antenna for WBAN applications. Using an S-shaped strip, a U-shaped strip, and an I-shaped strip, three operating bands covering 3.1-3.3, 4.2-4.9, and $6-10.6 \mathrm{GHz}$ for VSWR $\leqslant$ 2 are obtained. Measured VSWR and radiation patterns of the designed antenna agree reasonably well with simulations. Measurements show that the antenna is tolerant to bending when

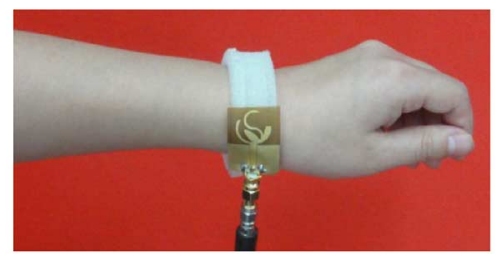

(a)

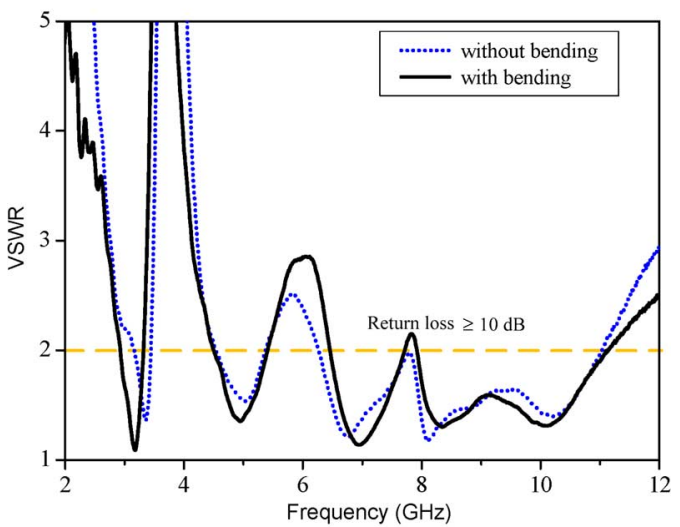

(b)

Fig. 10. Proposed antenna with bending and without bending. (a) Bending the antenna. (b) Measured and simulated VSWR.

conformed to arm, and the on-body measurements retain good VSWR characteristics.

\section{REFERENCES}

[1] A. W. Astrin, H. B. Li, and R. Kohno, "Standardization for body area networks," IEICE Trans. Commun., vol. E92-B, no. 2, pp. 366-372, Feb. 2009.

[2] C. H. Kang, S. J. Wu, and J. H. Tarng, "A novel folded UWB antenna for wireless body area network," IEEE Trans. Antennas Propag., vol. 60 , no. 2, pp. 1139-1142, Feb. 2012.

[3] J. R. Verbiest and G. A. E. Vandenbosch, "A novel small-size printed tapered monopole antenna for UWB WBAN," IEEE Antennas Wireless Propag. Lett., vol. 5, pp. 377-379, 2006.

[4] M. Klemm and G. Troester, "Textile UWB antennas for wireless body area networks," IEEE Trans. Antennas Propag., vol. 54, no. 11, pp. 3192-3197, Nov. 2006.

[5] S. S. Gao, S. Q. Xiao, D. P. Jin, and B. Z. Wang, "Wideband antenna for ultra-wideband (UWB) body-centric wireless communications," in Proc. IEEE Int. Conf. Ultra-Wideband, Nanjing, China, 2010, pp. 1-4.

[6] S. Hyuk, K. Jeongpyo, and C. Jaehoon, "A stair-shaped CPW-fed printed UWB antenna for wireless body area network," in Proc. Asia-Pacific Microw. Conf., Singapore, 2009, pp. 1965-1968.

[7] N. Chahat, M. Zhadobov, R. Sauleau, and K. Ito, "A compact UWB antenna for on-body applications," IEEE Trans. Antennas Propag., vol. 59, no. 4, pp. 1123-1131, Apr. 2011.

[8] A. Alomainy, A. Sani, J. Santas, A. Rahman, and Y. Hao, "Transient characteristics of wearable antennas and radio propagation channels for ultrawideband body-centric wireless communications," IEEE Trans. Antennas Propag., vol. 57, no. 4, pp. 875-884, Apr. 2009.

[9] H. Ghannoum, S. Bories, and R. D'Errico, "Small-size UWB planar antenna and its behaviour in WBAN/WPAN applications," in Proc. IET Seminar Ultra Wideband Syst., Technol. Appl., London, U.K., 2006, pp. 221-225

[10] T. S. P. See and Z. N. Chen, "Experimental characterization of UWB antennas for on-body communications," IEEE Trans. Antennas Propag., vol. 57, no. 4, pp. 866-874, Apr. 2009.

[11] C. A. Balanis, Antenna Theory: Analysis and Design, 3rd ed. New York: Wiley, 2005.

[12] S. Z. Zhu and R. Langlety, "Dual-band wearable textile antenna on an EBG substrate," IEEE Trans. Antennas Propag., vol. 57, no. 4, pp. 926-935, Apr. 2009. 